DOI: 10.1515/ausp-2016-0034

\title{
Leverage in Managing Future Translators
}

\author{
Attila IMRE \\ Sapientia Hungarian University of Transylvania \\ Department of Applied Linguistics, Târgu-Mureş, DAMERG Research Centre \\ attilaimre@ms.sapientia.ro
}

\begin{abstract}
The present paper offers an insight into the challenges of translation training within a young study programme. The introductory part mentions the revolution of the translation industry, which is connected to the technical advances, followed by a short presentation of the institution and the requirements of the Romanian Agency for Quality Assurance in Higher Education in this respect. Taking into consideration the market requirements for translators, possible leverage for future translators is presented through the prism of a practical course on translation technology, which is approached critically as well. The article ends with an outline of present-day skills and competences necessary for professional translators and possible conclusions.
\end{abstract}

Keywords: translation industry, translator training, management, skills and competences, criticism

\section{Introduction}

The idea for the present article partially comes from Gouadec's seminal book on translation-related issues (Gouadec 2007), in which he is an ardent supporter of translation embedded in technology. In our approach, his most important statement is that the "PRAT, or Pencil and Rubber-Assisted Translator is clearly on the way out... The Computer-Assisted Translator has taken over" (Gouadec 2007: 109). As we take it for granted that the (r)evolution of technology has led to a(n) (r)evolution in the field of translation as well (Imre 2013), we consider it vital to be conscious of the developments in this area if we have it in mind to enter or remain within the translation industry.

There are obvious signs that translation has grown into a fully-fledged industry in the second part of the $20^{\text {th }}$ century, which is still expanding in the $21^{\text {st }}$ century due to globalization and localization (Esselink 2000), and an EU report states that recess had little effect on the language-related market, which was estimated 
to reach above 20 billion $€$ by 2015 ; in fact, 5.7 billion $€$ in 2008 is "an assumed value of the translation and interpreting sector comprising software localisation and website globalisation activities" (Rinsche \& Portera-Zanotti 2009).

The effects of this growth are also visible at university level as more and more departments offer training/education in translation studies, and these study programmes aim at successfully preparing future translators and interpreters. In order to achieve the goal, teachers, trainers, and experts have to consider the market requirements, which reshaped the skills and competences of a translation service provider, demonstrated by the mushrooming of books on the topic: Kis \& Mohácsi-Gorove, 2008; Bowker, 2002; Dimitriu \& Freigang, 2008; McKay, 2006; Samuelsson-Brown, 2004, to name but a few. Their and others' concordant opinion is that long-established skills and competences (cf. language, communication and cultural) should be extended to include technical and (selfand client) management skills as well. Sadly, these skills are directly connected to financial possibilities, on the one hand, whereas this is still not enough to resist competition as personal skills might make the difference, such as adaptability, persistence, or discipline (e.g. always respecting the deadline), on the other hand.

Although education centres try to handle the situation, one may realize that there are certain impediments if we do not break down the training into certain courses and modules. In this respect, further food for thought was offered by Knops' article (Knops 2008), in which such an attempt is minutely described. In a similar vein, we would like to present how we are trying to offer students an insight into the recent developments in translation technology.

\section{The "start"}

The Translator and Interpreter BA study programme came into being in 2008 at Sapientia University, ${ }^{1}$ and at present is run by the Department of Applied Linguistics, Faculty of Human and Technical Sciences, Târgu-Mureş, Romania. According to the law, The Romanian Agency for Quality Assurance in Higher Education (Romanian acronym: ARACIS) is in charge of regular quality checks in all higher education institutions, state or private ones, ${ }^{2}$ being member of the "European Association for Quality Assurance in Higher Education - ENQA and ... registered in the European Quality Assurance Register for Higher Education - EQAR”.

As such, after a new study programme is established, ARACIS is entitled to grant or refuse accreditation when three generations of students have successfully passed their state examinations. The Agency "correlates higher education with the labour market", and thus institutions have to prove that their previous

1 Thanks to the efforts of late Prof. Olga Murvai, to whom we dedicate this article.

2 http://www.aracis.ro/nc/en/aracis/, 02.03.2016. 
students obtained jobs according to their qualifications during a limited period of time (two or three years), even if private universities can obtain no funds from the state. As the competition is significantly more serious on both global and local levels, all Romanian universities must do their best to have enough students. ${ }^{3}$ Consequently, our department must prove that it can offer at least an acceptable quality compared to other similar study programmes, and we underwent an ARACIS evaluation in 2014. Although we obtained the accreditation for the next five years, it does not mean that nothing is to be done till then.

From the very beginning, we have been trying to follow the latest trends in translation studies, realizing the fact that translation is more and more embedded into a localized business process, in which translators only take part if they have the necessary technical skills. Thus, we try to develop and shape a curriculum which takes into consideration those skills and competences of a translator which actually makes the difference between a non-professional and a professional translator. In our opinion, this is the knowledge of cutting edge technology in the field, combined and balanced with proper managerial skills. Seemingly, these skills are less obvious in translator training than others (cf. language and cultural competence); thus, we tend to think that their importance is vital in shaping a successful future translator. In these lights, we are more than indebted to Kilgray Company, ${ }^{4}$ which has been providing us their cutting edge translation environment, memoQ, since 2009.

On the other hand, the University provides well-equipped laboratories with both desktop computers and notebooks (a mobile laboratory for future translators) having installed up-to-date desktop publishing (DTP) software, such as Microsoft Office and Open/LibreOffice. However, after the first weeks have passed, the overwhelming majority of students use their own notebooks with the proper software, realizing that it is more convenient for class and homework activities.

\section{A practical course on translation technology}

Although students undergo an IT-related course (primarily focusing on DTP), its content is corroborated with the special needs translators may use as freelancers (also as proofreading and editing).

The course is taken further during a practical course activity, when students are presented technical issues related to translation. The course is set in a bilingual framework (with three possible specializations: Hungarian-English, Hungarian-

$3 \quad$ For a couple of years, there have been fewer pupils who obtain their GCSE than the total number of available university places per year, and many study programmes do not start due to the lack of students.

4 https://www.memoq.com/partnership/programs/academic-program/members, 02.03.2016. 
German, and Hungarian-Romanian), and after a brief introduction (clarifying the topics and requirements, definitions of translation, translator, and interpreter) students are familiarized with computer hardware for translators. We focus on those parts that are relevant for the software used by translators: processor, memory, or certain peripherals, such as the monitor (size) or keyboard (layouts) for particular language combinations.

The primary aim of this part is to make them aware of a possible future investment, and during the course websites in Romania, Hungary, and the United States ${ }^{5}$ are compared to check for prices of desktop computers and notebooks. This already leads us to the next section, when computer software is detailed, highlighting the financial advantage of buying notebooks with a pre-installed Microsoft Windows operating system. Although this type of operating system has major drawbacks (e.g. price or viruses), future translators are in no position of choosing a different one (for instance, a Linux-based one) due to the fact that - for the time being - prospective clients tend to use Microsoft Windows. As a result, the choice of other software is a corollary to this one, although in particular cases cross-platform software is discussed or mentioned (e.g. LibreOffice, OmegaT).

As for Microsoft Office (MSO), its most important features are known for the students, but certain aspects are highlighted, such as language settings for proofreading, which is compared to LibreOffice's (LO) proofreading options, and conclusions are drawn based on various samples. MSO Excel is used to create the first bilingual term bases (TB) and sorting and filtering options are also discussed in the case of large databases.

Furthermore, the concept of add-ins for MSO and LO are discussed, such as Zotero bibliographic management software (cross-platform) or Foxit Reader for MSO (they are already familiar with Adobe Reader), leading the students to the importance of .pdf documents. As there are more and more of this type of documents, their origin is to be checked (e.g. searchable, encrypted, how to add comments), discussing the conditions how translation software can import them before translation. Although we tend to think that $A B B Y Y$ PDF Transformer is one of the best .pdf handling software for converting non-searchable .pdf documents to searchable ones, there is no possibility to try it in the institutionalized setting, even if students are encouraged to test it. ${ }^{6}$

We are also aware of the fact that massive criticism has been formulated regarding translator training within the university framework; one of the strongest arguments is exactly the lack of top-notch software used in the translation industry; still, we think that trial versions, similar or free software (e.g. PDF Sam

5 For example, http://www.bestbuy.com/, reflecting the tendency of students to apply for Student Travel programmes in the United States of America and return home with notebooks bought there. 
for splitting and merging documents) can endow students with proper skills to handle new software later without investing too much during the training period. Furthermore, translation agencies or clients work with diverse DTS or translation software, and future translators can decide later which software is worth the investment (e.g. the moment they start profiting from a particular software).

At this stage, students are almost ready to carry out their first (classical) individual translation projects, as they know the MSO-based translation (dual columns, left-hand side for source text, right-hand side for target text), TB in .xlsx format (with entries from reputable published or online dictionaries), all checked for typing errors. Yet, before this task, the ethics of e-mail writing is discussed, offering poor and better examples how to formulate the salutation, the content and the ending of an electronic mail to possible clients, including only relevant and professional information (contact details, pricing, politeness), in accordance with the literature in the field (e.g. Kis \& Mohácsi-Gorove 2008, McKay 2006, Samuelsson-Brown 2004).

The evaluation of individual projects usually leads to the discussion of machine translation (MT) quality, as some of them make (extensive) use of it (especially Google Translator, GT), seemingly not realizing that the teacher will instantly spot these 'translations' due to their poor quality. Actually, this may already signal that some students will not live up to the expectations regarding translation quality. If time permits, a couple of samples are discussed, and students are left with a warning that machine translation - at its best - is a viable solution for gisting or finding nouns and adjectives (without inflections, e.g. in the case of Hungarian-English translations).

A further interesting test is when culture-specific words or expressions are translated with the help of MT, realizing that GT is 'effective' in 'all' language combinations due to the fact the it uses English as a relay language, a fact observed in other approaches as well:

Numerous languages as a result of the globalization of trade and technological development... most texts are written by teams rather than one author. The ST can be changed at any time (linguistic elegance, updates). English is the relay language, functioning as the modern lingua franca. ST has lost authority, and it also becomes an imprecise entity. This is most obvious in the instantaneous translations offered for free on the Internet (Dollerup 2005: 92).

After evaluating their individual translation projects, we proceed to the next level, focusing on translation with specially designed software, the memoQ translation environment.

Students are given individual keys to install the latest professional version on their notebooks during the class; in case they only have desktop computers, they 
install it at home and university notebooks are used during the class activities. Basic features are presented, starting from the concept of the translation tool enabling us to create a project in four steps:

1. creating the framework (e.g. name, title, language pair, client, content);

2. importing the document to be translated;

3. creating a translation memory (TM);

4. creating a term base (TB).

Further features are discussed depending on the group dynamics (number of students, their previous knowledge in the field), but central issues are always exemplified, such as Settings, Machine Translation options, Statistics, Spelling, Save, Shortcuts, Filter, Sort, Tags, Quality Assurance (QA), Export options, LiveDocs, and Backup options. Thus, students have the possibility to connect MSO- and LO-related issues within a memoQ project (language pairs, spelling, pre- and post-editing, how to write a quote based on source-text character/word count, etc.).

However, we do not wish to forget that this is an introductory course, and thus the quality of the translated text is less important than the technical know-how, as similarly expressed by Knops: "the focus of attention is more on the testing process and its methodology than on the test results" (Knops 2008: 190).

Having this in mind, a team translation project represents the final challenge for students during the course as they are supposed to work together in either one large group (translation of usually 30-100 pages of text) or in smaller groups of 5-8 people, depending on the task.

The deadline is not tight at all, as they usually have two weeks to translate 3-10 pages per person. Still, they are already acquainted with Kiraly's well-formulated truth: "The more time and effort I have to spend correcting a team member's work, the less valuable that work is to me as an employer and the less likely I am to employ that person again" (Kiraly 2005: 120). Yet, we should not forget Klaudy's remark: "the only correct criterion for quality assessment of students' translations is the amount of time required to transform them into print-ready texts" (Klaudy 1995: 202, Kiraly 2005: 119).

The team members decide themselves upon the roles in the team and they choose their own project manager, who is then responsible for the breakdown of the project and individual deadlines to fulfil the team project in due time. S/he is also in charge when 'technical issues' (inevitably) arise or members are behind schedule.

When a team translation project is over, students have to attach a report to their work, in which they evaluate their own job as well as their colleagues' who they came into contact with during the project: the project manager, terminologist(s), 
fellow translators, layout specialists, or proofreaders (cf. Kis \& Mohácsi-Gorove 2008: 247-328). Interestingly, rather objective remarks are born - one of the collateral benefits of a translation project; furthermore, each translator who has tried to "cheat" by providing only machine translation (most typically Google Translate) is severely frowned upon. The end of the project means that all members carried out their tasks, the project manager collected their work and finalized it with the help of the layout specialists and proofreaders. When working in memoQ, a translation project usually involves creating a TM and TB (to help an improved quality check), saving and exporting the target document in the same format as the original, and creating a bilingual .rtf file format as exemplified below:

Table 1. Team translation project sample in memoQ, group 8151E, Semester 1,2015

\begin{tabular}{|c|c|c|c|}
\hline \multicolumn{4}{|c|}{$\begin{array}{l}\text { Lindstrom-Martin-Buyology-2008-1-2-fejezet javitva.docx } \\
\text { CAUTION: Do not change segment ID or source text } \\
\text { MQ786611 0c361fb6-798f-4f94-ab2f-6bafbf75de37 }\end{array}$} \\
\hline English & Hungarian & Comment & Status \\
\hline 1 & 1 & & $\begin{array}{l}\text { Confirmed } \\
(101 \%)\end{array}$ \\
\hline $\begin{array}{l}\text { A RUSH OF BLOOD TO THE } \\
\text { HEAD }\end{array}$ & VÉRÁRADAT A FEJBE & & $\begin{array}{l}\text { Confirmed } \\
(101 \%)\end{array}$ \\
\hline $\begin{array}{l}\text { The Largest Neuromarketing } \\
\text { Study Ever Conducted }\end{array}$ & $\begin{array}{l}\text { A valaha készített } \\
\text { legnagyobb neuromarketing } \\
\text { tanulmány }\end{array}$ & & $\begin{array}{l}\text { Confirmed } \\
(101 \%)\end{array}$ \\
\hline $\begin{array}{l}\text { [1\}NOT SURPRISINGLY, THE } \\
\{2][3\} \text { smokers were on edge, } \\
\text { fidgety, not sure what to expect. } \\
\{4]\end{array}$ & $\begin{array}{l}\text { [1\}NEM MEGLEPÓ, HOGY\{2] } \\
\text { [3\}a dohányzók idegesek } \\
\text { voltak és nyugtalanok, nem } \\
\text { tudván mire számíthatnak.\{4] }\end{array}$ & & $\begin{array}{l}\text { Confirmed } \\
(101 \%)\end{array}$ \\
\hline $\begin{array}{l}{[1\}\{2][3\} \text { Barely noticing the }} \\
\text { rain and overcast skies, they } \\
\text { clumped together outside the } \\
\text { medical building in }\{4]\{\mathrm{MQ}\} \\
\text { London, England, that houses } \\
\text { the Centre for NeuroImaging } \\
\text { Sciences. }\end{array}$ & $\begin{array}{l}\text { [1\} \{2][3\}Figyelmen kívül } \\
\text { hagyva az esős, borús időt, } \\
\text { összegyúltek Londonban } \\
\text { a kórház előtt, \{4]\{MQ\} } \\
\text { amely az Agyi Képalkotási } \\
\text { Tudományok Központjának } \\
\text { ad helyet. }\end{array}$ & & $\begin{array}{l}\text { Confirmed } \\
(101 \%)\end{array}$ \\
\hline
\end{tabular}

While testing memoQ, students also realize that technical texts, manuals, brochures, etc. usually have no single authors, being the work of "a team or a number of authors who - as time passes and new things are added to the product in hand - include one or two new sentences in the ST describing new feature" as "the firm is unlikely to be willing to pay for a completely new translation" and "the modern language professional may not be given the larger context at all" (Dollerup 2006: 89). 
Although we are quite aware of the limitations of both individual and team translation projects during the course (cf. arguments that they are not 'life-like'), the majority of students are more than delighted to complete their tasks, which is 'life-like' enough for them to take it as seriously as possible. Consequently, students make use of all resources they know of during the project, in accordance with Pym's observation: “individual translators have to be able to generate and decide between alternatives, but it is rarely true that they have to do so entirely by themselves. In the training situation, the use of informants that is implicit in recourse to dictionaries and Internet resources is easily extended to the use of exchange students and academic specialists” (Pym 2003: 492), hoping that they realize that by the time they turn professional translators they need collaborators who are experts of a specific area (cf. Pym 2003).

A "full" translation project in memoQ (both individual and team-based) is handed in with five documents: the exported translation (1), the translation memory (2), the term base (3), the bilingual .rtf file (4), and the .mqbkf file (5), which is the backup file of the entire project, completed with the previously mentioned report. All these are collected and checked by the project manager and compressed in a .zip file, paying special attention to the total absence of language-specific diacritical marks in the electronic titles and sent via e-mail to the teacher or uploaded on the faculty's internal Moodle ${ }^{7}$ system.

We have to mention that the majority of students enjoy these tasks and are often proud to have completed their first team translation project, even if they feel that "they could have done it better". Yet, all these are subject to massive criticism, presented in the next section.

\section{Criticism of translation training}

Kiraly's criticism regarding translator training in class relies on Dollerup's proposal (only authentic texts be selected for use in class because they represent real-life translation problems) and Klaudy's claim:

[n]either real-life situational analysis, nor real-life text choice, nor occasional replacement of the teacher by the students can change the fact that, if the end user of the translation is the teacher, we cannot speak of professional translation in teaching; that is, unless the teacher plays the role of an editor or an editorial reviser (Klaudy 1995: 199).

However, a real-life text choice may make students aware what they are expected to translate under certain conditions and in a limited time frame. Trainers know 
that 'perfection' in translation is quite unlikely (due to various reasons as, for instance, subjectivity, before getting to language-related issues), whereas the above quotation seeks perfection. We believe that the mistakes that are committed during team translation may serve as a guide ${ }^{8}$ and encouragement should be given when successful parts of the project or of the translation are detected.

A further critical remark regarding translator education is that "teachers have little choice but to do unto their students as was done unto them" (Kiraly 2005: 122), and although this seems plausible it is easy to contradict. First, not all successful teachers were taught by successful teachers in their school years, so probably they have internalized both positive and negative role models (how to do and how not to do), a strategy to apply in translator training as well. Secondly, the advances in any field compel the professionals to keep up with the latest developments; in our case, we can mention the development of various translation tools over the past decade (MT, TB, TM, translation environments, to mention but a few). Yet, Kiraly goes further:

There are few if any "rules" for translators to follow; there are no commonly accepted inventories of techniques, strategies or procedures that need to be acquired through classroom exercises and implemented in clearly categorized problem situations; there are no translation methods, which, if carefully learned and applied, will lead the translator to the "right" solutions (Kiraly 2005: 122).

Kiraly's statement, however convincing it may seem at first, is not acceptable for multiple reasons. One of them is that, in his view, there are no commonly accepted inventories of techniques, strategies or procedures that need to be acquired. In fact, there are many studies and books on them, and even if they do not "need" to be acquired, their knowledge may prove useful in various circumstances such as omission in subtitling due to the constraints of this media type. And let us remember that no rules or regulations are "set in stone" in audiovisual translations either (Díaz-Cintas 2003: 198), so why should we have them in translation? Furthermore, the analysis of "accepted" and "successful" translations may lead to an improved quality in future translations. And we disagree that there are no rules for translators, having in mind both translator ethics and rules (written or unwritten) regarding cultural and linguistic constituents. We agree that neither of them can guarantee "right" solutions, but we do not think that translation should be compared to mathematics.

Dollerup defines "adequate" translation in terms of being convincing to the target-language audience (Dollerup 2005: 83), and we tend to think that the application of certain "rules" connected to translation (respecting deadlines,

8 Without 'serious' consequences and with the possibility of redressing the problem. 
proper spell-check, layout, TB and TM research, advanced knowledge of translation software) will be more convincing than a "trial and error" approach of self-taught translators, encouraged by Kiraly's criticism.

In our case, even if students do not have enough management skills at this stage (management for freelancers is discussed much later) and they cannot handle all types of source documents (e.g. audiovisual/multimedia translations are not discussed in details due to the limited amount of time for this course), they come to realize that professional translation takes more than "simple text translation", and both translation management and interpersonal issues come up. Dollerup admits that "[t]ranslation has always been more complex than scholars believed, but today, the sheer bulk and ubiquity of translation oblige us to face this fact" (Dollerup 2005: 91), and after a team translation project students have an experience-based knowledge of that.

Current "trends" involving translation, such as globalization and localization, are inevitably in the picture as well, as "editing is part and parcel of the process of localization" (Esselink, 2000 in Dollerup 2005: 90), for instance, converting foreign currencies, translating or preserving geographical names. Depending on the nature of the source texts, students recognize the truth in Dollerup's and Dimitriu's statements: "target texts may well be re-written independent of the source text wording” (Dollerup 2005: 90) and passages, parts of books may be left out (Dimitriu 2004: 170). At this stage, however, we should turn our attention to the skills and competences of a future translator.

\section{Skills and competences}

After having presented the practical course module, we should discuss the skills and competences aimed at during the course, which - at least in our opinion may offer considerable leverage for the students. We agree that "the knowledge and skills of the professional translator have always been particularly dependent on socio-cultural norms" (Kiraly 2005: 117); thus, it is worth listing those ones that seem to be relevant in the present.

Pym warns us that researchers "tend to ignore the more peripheral professional skills and the growing importance of teamwork" (Pym 2003: 486), and he establishes a "minimal" set of ability: generating a series of more than one viable target text (TT) and then selecting only one viable TT "quickly and with justified confidence" (Pym 2003: 488). However, the majority of researchers agree that next to linguistic and cultural (cf. extra-linguistic) skills other skills and competences must also be taken into consideration.

In our view, the concept of managing translators and translations may synthesize further skills: effective communication with prospective clients, self-management 
(advertising, respecting deadlines), technical skills (document management, IT knowledge), or taking decisions during the three phases: 1. pre-translation (e.g. accepting or refusing the job, planning the allotted time), 2. translation (e.g. strategies, such as Venuti's foreignization or register and style), and 3. posttranslation (e.g. format, layout, contacting clients - translation, invoice). Risku actually thinks that the translation student is an emerging text-design expert: "translations are, by definition, written for new situations, purposes, recipients and cultures. ... you have to learn how to position yourself in this communication system and define your own situational role, goal and tasks" (Risku 2002: 526).

While our course starts with computer hardware, it ends with a team translation project, during which we hope to raise awareness among students regarding the changing trends, namely that freelance translators must be more gregarious than before to ensure their participation in larger projects. But in order to understand the changed role of a translator, we should approach translation in a larger context, namely large globalization or localization projects, in which translation, however important, is not central. Having acknowledged this, a present-day professional translator must be familiar with certain IT skills and software, without which s/he is not even offered the chance to take part in these projects, such as website localizations or audiovisual translations. We must recognize that "pure text" translations are rare, except for literary translations, ${ }^{9}$ and even the translation of technical texts is connected with pictures, illustrations, logos, triggering layout constraints.

Even if the "market requires that the final product be of impeccable quality" (Kiraly 2005: 133), near-perfect solutions are easier to imagine (cf. the subjectivity of translations) and students are encouraged to offer consistent translations before the deadline.

\section{Conclusions}

We have to accept that the "on-the-go" attitude might eliminate us from the competition from the very beginning. As a result, we have to prepare students in such a way that they should be able to manage themselves and translations more successfully than non-professionals. For instance, a properly created CV should contain details of the education and experience in the field that can be more impressive from the start, based on serious technical education and management skills.

Romania is a country keen on technology and gadgets, although educational institutions can hardly keep up with the technological advancements. As a

9 According to estimates, less than $1 \%$ of all translations is connected to literary translations (McKay, 2006). 
result, those who can handle cutting edge technology have higher chances on the market.

A further deficiency is usually management-related: we tend to overlook the importance of a balanced self-management, which may lead to a similar client management. As our university is a small one, we think that our teachers monitor better students' needs to become professional translators compared to larger communities. In this respect, we completely agree with Knops that "satisfying the practical needs of students striving for a professional career" (Knops 2008: 186) should be the utmost aim of the course.

In fact, our students are faced with one of their first disenchantments on discovering the importance of computers for professional translators. We endeavor to offer our students the latest news about both hardware and software that might prove useful in the translation process, materializing in recently purchased equipment (notebooks for mobility, mobile interpretation system) and software (Microsoft Office and the yearly renewal of memoQ licences with Kilgray Company). Yet, we make them aware that software need constant updates and upgrades and preferences may change in favour of free software (Unix-based operating systems, LibreOffice, OmegaT, Localize, etc.).

As "sequels" to this introductory practical course, students are familiarized with different text types (technical, legal, etc.) and specific software for audiovisual translations (video-processing and subtitling) during further courses, which ends with a management module. Even if all these constitute a small set of industrystandard applications (cf. Knops 2008), it offers a rather realistic insight into the translation business.

The challenges mentioned by Knops in his concluding remarks, such as students' different linguistic skills and experience with computer applications (Knops 2008: 191), are to be observed in our environment as well. Yet, despite the discouraging difficulties, a number of our former students are competent translators now, leaving us with the hope that their number will grow steadily. 


\section{References}

Bowker, L. 2002. Computer-aided translation technology: a practical introduction. University of Ottawa Press.

Díaz-Cintas, J. 2003. Audiovisual translation in the third millennium. In: Translation today: trends and perspectives. Multilingual Matters. 192-204.

Dimitriu, R. 2004. Omission in translation. Perspectives: studies in translatology 12(3): 163-175.

Dimitriu, R.-Freigang, K.-H. (eds). 2008. Translation technology in translation classes. Iaşi: Institutul European.

Dollerup, C. 2005. Models and frameworks for discussing translation studies. In: K. Károly-Á. Fóris (eds), New trends in translation studies. In honour of Kinga Klaudy. Budapest: Akadémiai Kiadó. 75-93.

2006. Basics of translation studies. Iaşi: Institutul European.

Esselink, B. 2000. A practical guide to localization. John Benjamins Publishing.

Gouadec, D. 2007. Translation as a profession. John Benjamins Publishing.

Imre, A. 2013. Traps of translation. Braşov: Editura Universității “Transilvania”. Kiraly, D. 2005. Situating praxis in translator education. In: K. Károly-Á. Fóris (eds), New trends in translation studies. In honour of Kinga Klaudy. Budapest: Akadémiai Kiadó. 117-138.

Kis, B.-Mohácsi-Gorove, A. 2008. A fordító számítógépe. Bicske: Szak Kiadó.

Klaudy, K. 1995. Quality assessment in school vs. professional translation. In: C. Dollerup-V. Appel (eds), Teaching translation and interpretation 3: New horizons. Amsterdam: John Benjamins Publishing Company. 197-204.

Knops, U. 2008. Resource management for future translators and translation project managers. In: R. Dimitriu-K.-H. Freigang (eds), Translation technology in translation classes. Iaşi: Institutul European. 184-192.

McKay, C. 2006. How to succeed as a freelance translator. Lulu.com.

Pym, A. 2003. Redefining translation competence in an electronic age. In defence of a minimalist approach. Meta 48(4): 481-497.

Rinsche, A.-Portera-Zanotti, N. 2009. Study on the size of the language industry in the EU. Surrey: European Commission - DGT.

Risku, H. 2002. Situatedness in translation studies. Cognitive Systems Research 3(3): 523-533.

Samuelsson-Brown, G. (2004). A practical guide for translators ( $4^{\text {th }}$ ed.). Clevedon: Multilingual Matters. 